\title{
A Study of Students' Loneliness Levels and Their Attachment Styles
}

\author{
F. Sülen Şahin Kıralp ${ }^{1}$, Nergüz B. Serin ${ }^{2}$ \\ ${ }^{1}$ Faculty of Education, European University of Lefke, Cyprus \\ ${ }^{2}$ Faculty of Education, European University of Lefke, Cyprus \\ Correspondence: F. Sülen Şahin Kıralp, Psychologial Counseling Department, Faculty of Education, European \\ University of Lefke, Lefke, Cyprus.
}

Received: May 1, $2017 \quad$ Accepted: June 1, $2017 \quad$ Online Published: June 13, 2017

doi:10.11114/jets.v5i7.2395 URL: https://doi.org/10.11114/jets.v5i7.2395

\begin{abstract}
The purpose of this study was to examine the relationship between loneliness levels and attachment styles of university students. In this research, it was investigated whether the attachment styles differed in terms of variables such as gender, class, place of stay, socio-economic level of their family, parental education levels, counterpart friendship relations, number of siblings, whether to receive psychological help or not. This research was conducted as a relational search. A total of 247 university students selected randomly formed the sample of the research. The results of the research can be summarized as follows; Loneliness levels of those who perceive the socioeconomic status as low and those who didn't get psychological help are found to be higher. Male students and students who get psychological help have higher scores on secure attachment. According to the results of the research there's a low negative correlation between the loneliness levels of students and dismissing attachment style, a low positive correlation between the loneliness level and preoccupied attachment style, and a low negative correlation between the loneliness level and secure attachment style.
\end{abstract}

Keywords: loneliness, social relations, attachment, attachment theory, attachment styles

\section{Introduction}

\subsection{The Problem}

Contrary to past, as a result of advancements in technology and science social relations have started to emerge more in virtual environments than in real environments. Thus, there's a common view that in current themes, individuals have become lonelier and more alienated from each other. As a result of this, it is getting increasingly harder for individuals to establish healthy social relations. In other words, the problem of loneliness gets more and more widespread. Even though the experience changes from one person to another, today loneliness has become an indispensible aspect of modern world. However, as a psychosocial living being, a person would want to be close to others, establish relationships, share and be a meaningful part of somebody else's life.

An analysis of literature shows a variety of definitions for loneliness. Peplau and Perlman, (1982) indicate that there are 3 major aspects of these definitions on which the researchers have reached a consensus: 1) Loneliness is the outcome of the deficiencies in the social relations of an individual, 2) Loneliness is a private experience, 3) Loneliness is a disturbing and unpleasant experience. On the other hand, in their definition of loneliness, Peplau and Perlman draw attention to two main principles regarding loneliness 1) loneliness is a response to a discrepancy between desired and achieved levels of social contract and 2) in the cognitive process, attributions have a moderating influence on loneliness experiences (Peplau \& Perlman, 1982). Accordingly, loneliness has a cognitive aspect. In addition, attachment problems are among the major factors that result in the experience of loneliness. As it can be seen here, feeling of loneliness can be experienced in different ways and at different times by different individuals. For example, Schinka, VanDulmen, Bossarte and Swahn (2012) indicate that teenagers, who experience loneliness, have the tendency to talk more about depression, psychopathology and lack of social skills. Loneliness can be more obvious with the individuals who have deficit attachment figure or who experienced insufficient/concerned attachment situations in the past. And as a result, the individual would be deprived of the closeness and support to be provided otherwise by a person with whom he/she could share his/her life.

The first thing that comes to mind when reminded of attachment is the relationship that a newborn establishes with his/her mother. The baby who has certain needs ends up attachment with the person who meets his/her needs. At this 
point, one can observe the formation of attachment between the baby and the mother (or a caregiver in place of the mother). In order to better comprehend the concept of attachment, it would be helpful to take a look at the Attachment Theory.

It can be argued that Attachment Theory is based on the work of Bowlby and Ainsworth (1991). Even though the foundations of this theory have been laid before, the cooperation between two authors had started in 1950 (Bretherton, 1992). Attachment Theory carries traces of both developmental psychology and behavioral sciences as well as psychoanalysis. Attachment theory basically focuses on the bonding between the child and the mother. It also analyses the chaos experienced by the child when he/she is separated from or deprived of his/her mother or the caregiver that replaces the mother. Accordingly, the main idea of the philosophy is that a secure attachment to be established with the mother or the caregiver would have a positive influence on the relationships that the individual would have during the rest of his/her life. Humans naturally have the desire to be with others, trust them and be in contact with them. The need for attachment, which becomes more prevalent especially during moments of stress, is an expression of individual's desire to get rid of the problem and return to the state of security. In other words, when the individual is under stress, the desire to go back to the secure arms of the mother would emerge. While attachment forms the foundation of the early emotional development of the child, it can also be defined as a biological-social processes that aims to protect the child from environmental dangers. It can be said that the attachment theory comprises both personal and social traits and developmental traits. In light of this information, one can argue that different attachment styles develop as part of the attachment relationship. Attachment styles become shaped in early periods of life and are an expression of the individual's pattern for establishing relationships with others.

Bowlby (1969) indicates that every individual was born with an attachment style As attachment is one of the major dynamics of the socialization process, it is important to establish secure relationship with the others in the comingages (Erözkan, 2004). According to attachment theorists, once the attachment style is set as secure or insecure it continues like that for the rest of individual's life and influences his/her whole life. In other words, the attachment styles of the individual would have an impact on the behavior and attitudes that the individual demonstrates in his social and emotional relationships (Ekşi, Sevim, \& Kurt, 2016). Even though it is not the same in the following years, basic attachment style which is grounded during the infancy is important because it will be the model for the whole life of the individual. Different classifications of bonding styles exist in the literature. For example, Ainsworth et al. (1978) describes three differently attachment styles, namely; anxious/ambivalent, anxious/avoidant and secure. On the other hand, Hazan and Shaver (1987) define secure, avoidant and anxious attachment. Bartholomew and Horowits (1991) describe four types of attachment; secure, fearful, preoccupied and dismissing. Current study is based on the Four-Category Attachment Model developed by these researchers. In this model, self- and others-models are accepted as factors that determine the attachment styles. Here, self-model and others-models, being positive or negative would convey different meanings. Bartholomew and Horowitz (1991) describe it as follow: when the self-model and others-model are positive, there would be internalized self-esteem and the individual would consider him/herself as deserving love and seek closeness and support from others. When these are negative, on the other hand, the individual needs the approval of others refrains from getting close with others and have negative expectations from relationships. Combination of positive and negative poles with cognitive models, results in 4 different models.

Attachment and attachment styles are especially more important during adolescence years. Attachment becomes particularly important during the formation of the self-identity of the adolescent. The attachment style that the adolescent has would demonstrate itself in his self-identity, in his/her relationships with others, his/her harmony with his/her environment and the way he/she deals with problems he/she would come across. And this demonstrates once again, the importance of attachment styles. For example, situations when attachment is negative are seen as precursor for psychopathology (Kamkar, Doyle, \& Markiewicz, 2012). Accordingly, it is very important to analyze the personal, family-related and social factors that are believed to have an influence on the attachment styles of university students who are assumed to be in late adolescent period.

\subsection{Purpose}

The purpose of this study is to analyze the loneliness levels and attachment styles of university students and to demonstrate weather or not attachment styles and loneliness levels vary with variables of gender, year at college, residence location during education, socio-economic level of his/her family, education level of parents, the presence of someone special in their life, number of siblings, and whether or not the individual receives psychological support.

\section{Method}

\subsection{Research Design}

The data of this research, which examined the relationship between loneliness levels and attachment styles of university students, were collected during the spring semester of the 2016-2017 academic year. This study researches the 
relationship between the loneliness levels and attachment styles of university students. Thus, the study, which was carried out using a descriptive approach, was implemented in the form of relationship survey. The simple relational study design researches the relationship between two variables and then uses correlation analysis to define these relationships (Heppner, Wampold \& Kivlighan, 2013; Tekbiyık, 2015).

\subsection{Working Group/Participants}

Study sample comprises university students enrolled in the School of Education of a private university in Northern Cyprus. A total of 247 university students enrolled in different departments of the School of Education and were randomly selected constitute the study sample. $57.5 \%$ of the students enrolled in the study are female and $42.5 \%$ are male. In addition, $38.9 \%$ are freshman, $33.2 \%$ sophomore, $14.6 \%$ are junior and $13.4 \%$ are senior students. While $49.8 \%$ of the students in the study stated that they stayed in university dormitories, $80.2 \%$ stated that their families' socioeconomic status was avarage and $35.2 \%$ said that they had two siblings, $\% 36$ stated that their mothers were primary school graduates, $\% 30.4$ stated that their fathers were high school graduates, $\% 53.8$ stated that they have someone special in their life and $\% 90.3$ stated that they didn't get any psychological support.

\subsection{Data Collection Tools}

Data related to attachment styles in the study were collected using the Relationship Scales Questionnaire (RSQ). Relationship Scales Questionnaire (RSQ) was developed by Griffin and Bartholomew (1994). The scale was adapted to Turkish language by Sümer and Güngör (1999). The scale comprises 17 items. The internal consistency coefficient of the sub-scales of RSQ ranges between .27 and .61 . The correlations between the attachment styles as determined by the test retest reliability of the scale range between .54 and .78. Gül and Kararmak (2017) found internal consistency coefficient of the scale .78 in their research. On the other hand, Okur (2016) found the Cronbach Alfa coefficients for secure, fearful, avoidant and preoccupied subscales were $.47, .72, .60$ and .37 . These results indicate that the scale can be used in this study group. Responders were asked to evaluate each item as to how much every item affects them and their relationships using a 4-step scale. The scale aims to measure 4 attachment styles namely secure, dismissing, fearful and preoccupied. Accordingly, the respondents are placed in groups based on which scale they've received the highest score.

Levels of loneliness of university students were determined using UCLA Loneliness Scale. Even though the scale was originally developed by Russel, Peplau and Ferguson (1978), all its items were later revised by Russel, Peplau and Cutrona (1980). As a result, half of the items were made positive and half were made negative. The scale was adapted to Turkish by Demir (1989). The scale is 4 Point Likert scale and its scoring was arranged in a manner to correspond to 1-I never experience it, 2-I experience it rarely, 3-I sometimes experience, 4- I experience it frequently. Reliability of the test was determined using test retest method. Reliability coefficient is .94. For the validity of the test, Beck Depression inventory was checked and validity coefficient was calculated to be .82. In their study, Y1ldiz (2016) and Meral \& Bahar (2016) found the Cronbach's alpha internal consistency coefficient of the scale $.72, .83$. These results also indicate that the scale can be used in this study group.

\subsection{Data Analysis}

For analysis of data, in order to determine whether or not there's difference among groups, "t" test was used while "F" test was used for variables more than two. In order to determine from which groups the significant difference between variables stem from, "scheffe" significance test was applied. The Kolmogorov-Smirnov test was performed to determine whether the data were distributed normally. As a result, for non-parametrical measurements, Mann Whitney U test was used $(\mathrm{p}<0.05)$. For demonstrating the relationship between the students' attachment styles and their loneliness levels, Pearson Product-Moment Correlation method was used.

\section{Findings}

The findings based on the scores obtained from the loneliness scale can be summarized as follows: based on the responses of students to the loneliness scale, it was seen that loneliness scores of $54.3 \%$ of the students are above average. In addition it was seen that the average scores of the male students $(\bar{X}=45.30, S D=7.53, \min =29, \max =60)$ is slightly higher than the average scores of female students $(\overline{\mathrm{X}}=44.82, S D=7.81$, $\min =29, \max =62)$. Analysis of students' responses to the questions shows that $52 \%$ (129 respondents) responded as "Never experienced it", to the item "have no friend". On the other hand, $6.5 \%$ of the students responded as "Experience it frequently" to the item "I feel outcast from the group". 
Table 1. ANOVA results for the variance of students' loneliness levels based on their socioeconomic status

\begin{tabular}{llllll}
\hline & $S S$ & $d f$ & $M S$ & $F$ & $p$ \\
\hline Between Groups & 491.139 & 2 & 245.569 & 4.274 & .015 \\
Within groups & 14018.715 & 244 & 57.454 & & \\
Total & 14509.854 & 246 & & & \\
\hline
\end{tabular}

The analysis conducted showed a statistically significant variance among students' loneliness levels based on socioeconomic status $\left(\mathrm{F}_{(2-244)}=4.27, \mathrm{p}<.05\right)$. According to the results of Scheffe test carried out to find out from which group this difference stemmed from, the loneliness levels of those that perceived their socioeconomic levels as low were higher than those that perceived their socioeconomic situation as good and moderate. In other words, it can be argued that income level may result in loneliness being perceived or experienced differently by students

As seen in Table 2, students' loneliness levels also vary significantly based on whether or not they receive psychological support $(\mathrm{u}=1723, \mathrm{p}<.05)$. Looking at the rank averages, one can argue that the loneliness levels of those that didn't receive psychological support were higher than those that did.

Table 2. Mann Whitney $U$ test results for psychological help for loneliness levels

\begin{tabular}{l|l}
\hline Test Statistics & Loneliness \\
\hline Mann-Whitney U & 1723.000 \\
Wilcoxon W & 26699.000 \\
Z & -2.868 \\
Asymp. Sig. (2-tailed) & .004 \\
\hline
\end{tabular}

However, no statistically significant difference was observed between the other variables and loneliness levels in the study. No statistically significant difference was observed between loneliness level and year at college $\left(\mathrm{F}_{(245)}=.32\right.$, $\left.\mathrm{p}>.05\right)$, gender $\left(\mathrm{t}_{(245)}=.62, \mathrm{p}>.05\right)$, presence or absence of a significant other $\left(\mathrm{t}_{(245)}=.89, \mathrm{p}>.05\right)$, parents' education level (Mother $\mathrm{F}_{(245)}=1.87$, Father $\left.\mathrm{F}_{(245)}=.52, \mathrm{p}>.05\right)$, number of siblings $\left(\mathrm{F}_{(245)}=1.10, \mathrm{p}>.05\right)$, or place of residence $\left(\mathrm{F}_{(245)}=.24 \mathrm{p}>.05\right)$.

Analysis of the scores obtained from the responses given by students to the scale, in terms of the attachment styles, shows that $55.1 \%$ (136 people) demonstrated dismissing attachment $(\bar{x}=13.66, S D=2.27, \min =8, \max =18), 36.8 \%$ (91 people) demonstrated secure attachment $(\overline{\mathrm{x}}=12.93, S D=2.24$, $\min =5$, max $=18), 4.9 \%$ (12 people) demonstrated fearful attachment $(\overline{\mathrm{x}}=9.99, S D=2.19, \min =4, \max =15)$, and $3.2 \%$ (8 people) demonstrated preoccupied attachment $(\overline{\mathrm{x}}=9.57, S D=2.33$, $\min =4, \max =16)$.

Looking at the responses given by students to scale questions, in terms of each sub-scale, we see that the item among the sub-scale items that students agreed with the most often was the statement "I can easily establish emotional bonding with others" (42.1\%). Among the items that make up the fearful attachment sub-scale, students most frequently (38.5\%) agreed with the statement "I would be anxious that others might not value me as much as I value them". Among the items that make up the dismissing attachment sub-scale, students expressed agreement most frequently (49\%) with the expression "it is very important for me to feel independent".

Looking at the study findings in terms of attachment styles, statistically significant difference with gender was observed in secure attachment style $\left(t_{(245)}=3.16, \mathrm{p}<.05\right)$.

Table 3. T-test results for secure attachment style in relation to gender variable

\begin{tabular}{|c|c|c|c|c|c|c|}
\hline \multirow{2}{*}{$\begin{array}{l}\text { Attc. Style } \\
\text { Secure }\end{array}$} & Gender & $N$ & & $S D$ & $t$ & $p$ \\
\hline & Female & 142 & 12.5493 & 2.24581 & -3.16 & $\mathrm{P}<0.05$ \\
\hline & Male & 105 & 13.4476 & 2.14378 & & \\
\hline
\end{tabular}

As seen in Table 3, a statistically significant difference was observed in the direction of male students in terms of secure attachment style $\left(\mathrm{t}_{\text {secure }}=-3.16, \mathrm{p}<.05\right)$. However, no statistically significant difference was observed based on gender for the attachment styles of fearful attachment, preoccupied attachment, and dismissing attachment. $\left(\mathrm{t}_{\text {(fearful }}=1.21\right.$, $\mathrm{t}_{\text {(preoccupied) }}=-, 53, \mathrm{t}_{\text {(dismissing) }}=, 89, \mathrm{p}>.05$ ).

Another variable in the study whose effect on attachment styles was analyzed was whether or not the students received psychological support. Findings are given in Table 4.

Table 4. Mann-Whitney U test results according to the psychological assistance status of the secure attachment style

\begin{tabular}{l|l}
\hline Test Statistics & Secure Attac. \\
\hline Mann-Whitney U & 1467.000 \\
Wilcoxon W & 1767.000 \\
$\mathrm{Z}$ & -3.669 \\
Asymp. Sig. (2-tailed) & .000 \\
\hline
\end{tabular}

As seen in Table 4, a statistically significant difference was observed between secure attachment style and presence or absence of psychological support $(\mathrm{u}=1467, \mathrm{p}<.05)$. When the rank averages are taken into account, it can be argued that those that receive psychological support demonstrated secure attachment style more frequently. However, no statistically 
significant difference was observed between preoccupied attachment and dismissing attachment on the bases of presence or absence of psychological support ( $\mathrm{p}>.05$ ).

Based on the data obtained in the study with regard to attachment styles, no statistically significant difference was observed between the sub-scales of attachment and year at college $\left(\mathrm{F}_{(\mathrm{S})}=.90, \mathrm{~F}_{(\mathrm{F})}=1.16, \mathrm{~F}_{(\mathrm{P})}=.61, \mathrm{~F}_{(\mathrm{D})}=.15, \mathrm{p}>.05\right)$, socio-economical level $\left(\mathrm{F}_{(\mathrm{S})}=1.04, \mathrm{~F}_{(\mathrm{F})}=.64, \mathrm{~F}_{(\mathrm{P})}=15, \mathrm{~F}_{(\mathrm{D})}=.50 \mathrm{p}>.05\right)$, presence or absence of a significant other $\left(\mathrm{t}_{(\mathrm{S})}=1.13\right.$, $\left.\mathrm{t}_{(\mathrm{F})}=.25, \mathrm{t}_{(\mathrm{P})}=73, \mathrm{t}_{(\mathrm{D})}=1.22 \mathrm{p}>.05\right)$, parents' education level $\left(\right.$ Mother $\left.\mathrm{F}_{(\mathrm{S})}=1.35, \mathrm{~F}_{(\mathrm{F})}=1.48, \mathrm{~F}_{(\mathrm{P})}=1.96 \mathrm{~F}_{(\mathrm{D})}=1.44, \mathrm{p}>.05\right)$ $\left(\mathrm{FatherF}_{(\mathrm{S})}=.76, \mathrm{~F}_{(\mathrm{F})}=1.21, \mathrm{~F}_{(\mathrm{P})}=1,53, \mathrm{~F}_{(\mathrm{D})}=1.48, \mathrm{p}>.05\right)$, number of siblings $\left(\mathrm{F}_{(\mathrm{S})}=.69, \mathrm{~F}_{(\mathrm{F})}=.33, \mathrm{~F}_{(\mathrm{P})}=2.27, \mathrm{~F}_{(\mathrm{D})}=.36 \mathrm{p}>.05\right)$, place of residence $\left(\mathrm{F}_{(\mathrm{S})}=.61, \mathrm{~F}_{(\mathrm{F})}=.78, \mathrm{~F}_{(\mathrm{P})}=1.01, \mathrm{~F}_{(\mathrm{D})}=1.03 \mathrm{p}>.05\right)$.

Another question that the study aimed to answer was whether or not there was a statistically significant correlation between loneliness level and attachment style. Findings are given in Table 5.

Table 5. Relationship between loneliness levels and attachment styles

\begin{tabular}{|c|c|c|c|}
\hline & & Loneliness & Dismissing \\
\hline DISSMISSING & $\begin{array}{l}\text { Pearson Correlation } \\
\text { Sig. (2-tailed) } \\
\text { N } \\
\text { Pearson Correlation } \\
\text { Sig. (2-tailed) } \\
\text { N }\end{array}$ & $\begin{array}{l}1 \\
247 \\
-.223 * * \\
.000 \\
247\end{array}$ & $\begin{array}{l}-.223 \\
.000 \\
247 \\
1 \\
247\end{array}$ \\
\hline & & Loneliness & Preoccupied \\
\hline LONELINESS & $\begin{array}{l}\text { Pearson Correlation } \\
\text { Sig. (2-tailed) } \\
\text { N } \\
\text { Pearson Correlation } \\
\text { Sig. (2-tailed) } \\
\text { N }\end{array}$ & $\begin{array}{l}1 \\
247 \\
.154^{*} \\
.016 \\
247 \\
\end{array}$ & $\begin{array}{l}.154^{*} \\
.016 \\
247 \\
1 \\
247 \\
\end{array}$ \\
\hline & & Lonelines & Secure \\
\hline $\begin{array}{l}\text { LONELINESS } \\
\text { SECURE }\end{array}$ & $\begin{array}{l}\text { Pearson Correlation } \\
\text { Sig. (2-tailed) } \\
\text { N } \\
\text { Pearson Correlation } \\
\text { Sig. (2-tailed) } \\
\text { N }\end{array}$ & $\begin{array}{l}1 \\
247 \\
-.125 * \\
.049 \\
247 \\
\end{array}$ & $\begin{array}{l}-.125^{*} \\
.049 \\
247 \\
1 \\
247 \\
\end{array}$ \\
\hline
\end{tabular}

**. Correlation is significant at the 0.01 level (2-tailed).

*. Correlation is significant at the 0.05 level (2-tailed).

As seen in Table 5, there's a low negative correlation between the loneliness levels of students and dismissing attachment style $(\mathrm{r}=-0.223, \mathrm{p}<.01)$, a low positive correlation between the loneliness level and preoccupied attachment style $(\mathrm{r}=0.154, \mathrm{p}<.05)$, and a low negative correlation between the loneliness level and secure attachment style $(\mathrm{r}=-0.125, \mathrm{p}<.05)$. No statistically significant relationship was observed between fearful attachment and loneliness level.

\section{Discussion, Conclusion \& Suggestions}

As we all know, the first attachment that a newborn establishes is the one with the newborn and the mother/caregiver. Over time, this attachment can be internalized and may affect the relationships that the individual may establish with others in the future. In the literature, in addition to studies that demonstrate that the infancy attachment continues unchanged in individual's relationships as an adult as well (for example Ainsworth et al. 1978), there are also studies that demonstrate that these two attachment styles are different from each other (for example Weiss, 1982). Both of these studies have been mentioned particularly because they are among the most important studies conducted ever in this area. In this study, moving from the view that the first attachment with the mother would influence the individual's relationships with others as well, and by taking as basis, the Four-Category Attachment Model of Bartholomew and Horowitz (1991), the attachment styles of young people and their loneliness levels as well as the relationship between these were analyzed on the basis of certain sociocultural and economic variables.

It was observed that majority of the students in the study demonstrated dismissing attachment style. Individuals with dismissing attachment style would tend to be more autonomous individuals. They don't like to be dependent on others. They refrain from establishing close emotional bonding with others. The responses given by the students to survey questions related to dismissing attachment style, show that the most frequently selected item was the expression "it is very important for me to feel independent". According to Bartholomew \& Horowitz (1991), while these individuals have positive self-schemas, their schemas of others would be negative. It was seen that preoccupied attachment is the least frequently observed attachment style among the students in the study. People with preoccupied attachment style 
would perceive themselves as being worthless. Unlike the dismissing attachment style, they would have negative self-schemas and positive schemas of others (Bartholomew \& Horowitz, 1991). Based on these results it was seen that the attachment style that best describes the university students enrolled in the study are dismissing attachment, secure attachment, fearful attachment and preoccupied attachment respectively. As mentioned by Morsünbül and Çok, 2011, adolescents would be in a struggle to be less dependent on the initial attachment figure. The fact that the participants of this study were studying in a foreign country, and the fact that they were living away from their families can be thought to be factors resulting in this conclusion. Because all of the students that accept to participate in the study were students that came to Northern Cyprus for education. Their separation from their families and lack of family support might have encouraged them to be more self-sufficient. However, considering the fact that attachment style develops over time starting from infancy, the situation that comes to mind is where the traits of the attachment figure of the child, child's relationship with this figure and the self-identity model all complement each other. In other words, it can be argued that the quality of this relationship with the figure may be supporting the individual's disinterest towards intimacy. Of course one shouldn't neglect the fact that there might be cultural factors involved as well.

Looking at attachment styles in terms of variables of gender and absence or presence of psychological support, it can be argued that male participants and those that receive psychological support demonstrate traits specific to secure attachment style. Erözkan $(2004,2011)$ and Bartholomew and Horowitz (1991) and Çetinkaya (2005) have reached a similar conclusion in their respective studies as well. In general, individuals with secure attachment styles perceive themselves as deserving value and love. Because of this, they would be more willing to reach both themselves and others. And this is accepted as the individual seeking psychological support. In addition, it can be argued that the relationships established by those that have secure attachment styles would be more relying on mutual confidence. It can be argued that this situation makes it easier to receive psychological support and that receiving psychological support makes positive contribution to this situation. Because the studies have shown that attachment styles are related to psychological indications (Gündüz, 2013). In addition, in Turkish society, boys would be more encouraged to become as valued individuals who have self-confidence. Thus it is believed that, in addition to parents' approach to child upbringing, society's attitude towards gender roles support this outcome as well.

Other variables whose effects on the attachment style were researched in the study were found to have no statistically significant relationship with attachment style. Similar findings have been found in the literature in relation to variables of college year (Erözkan, 2004), socio economical status of the family (Çağatay, 2014), parents' education level (Karaşar, 2014) and number of siblings (Çağatay, 2014).

Even though study participants have expressed disagreement with the expression "I have no friends" in the scale, looking at the loneliness scores, it was seen that loneliness scores of $54.3 \%$ of them are higher than average. It is also seen that some studies carried out with adolescents have reached similar findings as well (Baran, Baran, \& Maskan, 2015; Schinka et al., 2012). This may be related to students demonstrating mostly dismissing attachment style. According to Weiss (1982), loneliness can be analyzed under two main topics of social and emotional loneliness. While social loneliness is more about lack of social relations, emotional loneliness is related to lack of sincerity in social relations. Feeling of loneliness experienced maybe due to both of these reasons. Living in a foreign country, difficulty to establish friendships with individuals from other cultures, cultural differences and being away from the family with which the individual established the first real bonding, may have resulted in this outcome. Even though the average loneliness scores of male students in this study may seem to be higher than the scores of female students, no statistical significance was observed. There are other studies in the literature that support this finding such as Çeçen, 2008; Erözkan, 2009; Oruç, 2013; Kılıç, 2014;Özçelik, İmamoğlu, Çekin, \& Başpınar, 2015; Certel, Yakut, Yakut \& Gülsün, 2016). Accordingly, one may think that loneliness does not correlate with gender.

It was seen that the students that perceive their families' socioeconomic status to be lower tend to have a higher level of loneliness. In the literature there are other studies that support this finding. For example (Baran et al., 2015) the loneliness levels of those with lower income levels were found to be higher. On the other hand, Gürsoy and Biçakçı (2006) showed that loneliness level decreased as the income level of the family increased. Similar findings were reached by Duyan et al (2008) as well. It may be thought that better financial situation of the family results in the young person to have higher self-confidence and have fewer concerns for the future. It can also be assumed that the person will have more opportunities for socialization and for benefiting from the opportunities offered by his/her environment. And these are accepted as factors resulting in lower sense of loneliness in those that have better socio economical status.

Based on the study findings, it was seen that university students that do not receive psychological support tend to have a higher level of loneliness. It is argued that early childhood experiences that contribute to loneliness may be predictive of loneliness in adult years (Erözkan, 2004). In the literature, there are studies that show that loneliness level increases parallel to hopelessness (Baran et al., 2015). It can be argued that those that are not very good at entering into relationships with people around them, those with low sense of self, those that have gone through a sudden and big 
change in their lives (for example the death of a loved one or a divorce) may feel higher levels of loneliness. Such people are in fact those that may benefit most from the psychosocial support services. Thus, it may be thought that those that don't receive psychological support are not able to benefit from a relationship to be established during this consultancy that is based on mutual trust.

No statistically significant results were reached with regard to other variables that influence loneliness levels in the study. In the literature there are studies that have reached similar results based on the variables of college year (Atlı \& Keldal, 2015; Baran et al., 2015; Certel, Yakut, Yakut \& Gülsün, 2016), parent's education level (Uruk \& Demir, 2003; Baran et al., 2015), and number of siblings (Uruk \& Demir, 2003; Baran et al., 2015).

One of the questions that the study aimed to find an answer was whether or not there was a relationship between attachment styles and loneliness levels. Analyses conducted have shown that there is a positive correlation between loneliness level and preoccupied attachment, and a negative correlation between loneliness and dismissing attachment and secure attachment. The fact that those with dismissing attachment have internalized autonomy and not being dependent on others and that those with secure attachment have a tendency to establish fulfilling relationship structures in their relations with others, actually explain these findings. Those with preoccupied attachment style wouldn't perceive themselves as being worth to be loved and constantly seek approval from their surroundings. And this explains the positive correlation between loneliness level and preoccupied attachment. It seems that as the loneliness level increases, so does the tendency to have preoccupied attachment style.

Consequently, especially the weak relationships in secure attachment, may refrain individuals from being with others, seeking support or sharing and this may result in loneliness. In current times, especially with the influence of technology, loneliness has emerged as an undesired situation for humans. The feeling of loneliness, which may manifest itself as lack of social relations, should be analyzed from the perspective of the family as well. In the literature, there are studies showing that especially those young people with a secure attachment with their families during their adolescence, had better relations with their friends and felt socially more competent and had higher level of self-esteem (For example Sümer \& Güngör, 1999). On the other hand lower sense of attachment results in individuals experiencing loneliness in the face of negative life events and challenges they face. And their attachment styles play an important role in their ability to develop close relations. Thus, the parental attitudes demonstrated by the adolescent's parents during the attachment period and the social support perceived by the adolescent as a result of this could be a study topic for future research endeavors.

The study can be carried out with a larger sample (like all university students in Northern Cyprus) and students may be provided psychological support services by the Guidance and Counseling Service of the universities based on the study results. For instance, there are studies that sports activities result in lower loneliness levels (Özçelik et al., 2015). One option may be creating more such activities with students in the campus. Students maybe provided psychological support by organizing tournaments among different classes or by organizing different activities among departments.

\section{References}

Ainsworth, M. D. S., Blehar, M. C., Walters, E., \& Wall, S. (1978). Patterns of attachment: A psychological study of the strange situation. Hillsdale, NJ: Lawrence Erlbaum Associates, Inc..

Ainsworth, M. D. S., \& Bowlby, J. (1991). An ethological approach to personality development. American Psychologist, 46, 331-341. https://doi.org/10.1037/0003-066X.46.4.333

Atli, A., Keldal G., \& Sonar, O. (2015). The relationship between the levels of university students' alienation and loneliness. Mustafa Kemal University Journal of Graduate School of Social Sciences, 12(29), 149-160. https://doi.org/10.17155/spd.18840

Baran, M., Baran, M., \& Maskan, A. (2015). a study on adolescent students' levels of hopelessness, loneliness and self-esteem: a sample from Turkey. Mediterranean Journal of Social Sciences, 6, 341-353. https://doi.org/10.5901/mjss.2015.v6n2s1p341

Bartholomew, K., \& Horowitz, L. M. (1991). Attachment styles among young adults: a test of a four category model. Journal of Personality and Social Psychology, 62(2), 226-244. https://doi.org/10.1037/0022-3514.61.2.226

Bowlby, J. (1969). Attachment and loss: Vol. 1. Attachment. New York: Basic Books.

Bretherton, I. (1992). The origins of attachment theory: John Bowlby and Mary Ainsworth. Developmental Psychology, 28, 759-775. https://doi.org/10.1037/0012-1649.28.5.759

Certel, H., Yakut, S., Yakut, İ., \& Gülsün, B. (2016). Loneliness problem in students. Journal of the Human and Social Science Researchers, 5, 3069-3084.

Çağatay, S. E. (2014). The relationship between level of childhood traumatic experiences, attachment styles and defence 
mechanisms among university students (Unpublished master's thesis). İstanbul Arel University, Istanbul, Turkey.

Çeçen, A. R. (2008). University students' loneliness and perceived social support levels according to gender and perceived parents' attitudes. Journal of Turkish Educational Sciences, 6(3), 415-431.

Çetinkaya, B. (2005). The relationship between university students'self- disclosure and attachment styles. (Unpublished $\mathrm{PhD}$ thesis). Atatürk University, Erzurum, Turkey.

Demir, A. (1989). The validity and reliability of UCLA Loneliness Scale. Journal of Psychology, 7(23), 14-18.

Duyan, V., Çamur, D. G., Gökçearslan, Ç. E., Sevin, Ç., Erbay, E., \& Ikizoğlu, M. (2008). An examination of variables affecting state of loneliness in high school students. Education and Science, 33(150), 28-41.

Ekşi, H., Sevim, E., \& Kurt, B. (2016). Psychological birth order and inferiority feeling as predictors of adult attachment style. Elementary Education Online, 15, 1054-1065. https://doi.org/10.17051/io.2016.90300

Erözkan, A. (2004). Examining the attachment style and loneliness levels of high school students according to some variables. Atatürk University Journal of Graduate School of Social Sciences, 4, 155-175.

Erözkan, A. (2009). Predictors of loneliness in adolescents, Elementary Education Online, 8 (3), 809-819. Retrieved from http://dergipark.gov.tr/ilkonline/issue/8597/106998

Erözkan, A. (2011). Attachment styles and decision making strategies of university students. International Journal of Eurasia Social Sciences, 2(3), 60-74.

Griffin, D., \& Bartholomew, K. (1994). Models of the self and other: Fundamental dimensions underlying measures of adult attachment. Journal of Personality and Social Psychology, 67, 430-445. https://doi.org/10.1037/0022-3514.67.3.430

Güloğlu, B., \& Kararrmak, Ö. (2017). Attachment styles and psychological tendencies in intimate relations in paternal loss in early childhood. Turkish Psychological Counseling and Guidance Journal, 7, 99-115.

Gündüz, B. (2013). The contributions of attachment styles, irrational beliefs and psychological symptoms to the prediction of cognitive flexibility. Educational Sciences: Theory \& Practice, 13, 2079-2085. https://doi.org/10.12738/estp.2013.4.1702

Gürsoy, F., \& Bıçakçı, M. Y. (2006). A study on loneliness level of adolescents. Journal of Qafgaz, 1, 140-146.

Hazan, C., \& Shaver, P. R. (1987). Romantic love conceptualized as an attachment process. Journal of Personality and Social Psychology, 52(3), 511-524. https://doi.org/10.1037/0022-3514.52.3.511

Heppner, P. P., Wampold, B. E., \& Kivlighan, D. M. (2013). Research design in counseling (translation ed. D. M. Siyez). Ankara: mentis Publication.

Kamkar, K., Doyle, A. B., \& Markiewicz, D. (2012). Insecure attachment to parents and depressive symptoms in early adolescence: Mediating roles of attributions and self-esteem. International Journal of Psychological Studies, 4(2), 3-18. https://doi.org/10.5539/ijps.v4n2p3

Karaşar, B. (2014). Attachment styles and social anxiety levels of teacher candidates. Amasya Educational Journal, 3(1), 27-49.

Kılıç, Ş. D. (2014). Analysis on the loneliness and psychological resilience of undergraduate student (Unpublished master's thesis). Atatürk University, Erzurum, Turkey.

Meral, D., \& Bahar, H. H. (2016). Investgating the relationship between problematic internet use and psychological well being and loneliness in secondary education students. Erzincan University Journal of Educational Faculty, 18, 1117-1134.

Morsunbul, U., \& Çok, F. (2011). Attachment and related variables. Current Approaches in Psychiatry, 3, 553-570. https://doi.org/10.5455/cap.20110324

Okur, Ö. (2016). Effects of perceived parental conflict, perceived parental styles and attachment styles on romantic relationship attitudes and life satisfaction (Unpublished master's thesis). Middle East Technical University, Ankara, Turkey

Oruç, T. (2013). Research on the relation between loneliness and automatical thoughts of university students related with psychosocial variables (Unpublished master's thesis). Dokuz Eylül University, İzmir, Turkey.

Özçelik, İ., İmamoğlu, O., Çekin, R., \& Başpınar, S. G. (2015). The effect of sports on the university students' level of loneliness. Journal of Sports and Performance Researcers, 6(1), 12-18.

Peplau, L. A., \& Perlman, D. (1982). Perspectives on Loneliness. Loneliness: A Sourcebook of Current Theory, 
Research and Therapy. https://doi.org/10.2307/2068915

Russell, D., Peplau, L. A., \& Ferguson, M. L. (1978). Developing a measure of loneliness. Journal of Personality Assessment, 42, 290-294. https://doi.org/10.1207/s15327752jpa4203_11

Russell, D., Peplau, L. A., \& Cutrona, C. E. (1980). The revised UCLA Loneliness Scale: concurrent and dsriminant validity evidence. Journal of Personality and Sociaş Psychology, 39, 472-480. https://doi.org/10.1037/0022-3514.39.3.472

Schinka, K. C., VanDulmen, M. H. M., Bossarte, R., \& Swahn, M. (2012). Association between loneliness and suicidality during middle childhood and adolescence: Longitudinal effects and the role of demographic characteristics. The Journal of Psychology, 146, 105-118. https://doi.org/10.1080/00223980.2011.584084

Sümer, N., \& Güngör, D. (1999). Psychometric evaluation of adult attachment measures on Turkish Samples and a cross-cultural comparison. Turkish Journal of Psychology, 14(43), 71-106.

Tekbiyık, A. (2015). Relational research method. In M. Metin (Ed.), Research methods (pp.99-114). Ankara: Pegem Academy.

Uruk, A. C., \& Demir, A. (2003). The role of peers and families in predicting the loneliness level of adolescents. The Journal of Psychology, 137(2), 179-193. https://doi.org/10.1080/00223980309600607

Weiss, R. S. (1982). Attachment in adult life. In C. M. Parkes \& J. Stevenson-Hinde (Eds.), The place of attachment in human behavior (pp. 171-184). New York: Basic Books.

Yıldiz, M. A. (2016). Multiple mediation of emotion regulation strategies in the relationship between loneliness and positivity in adolescents. Education and Science, 41, 217-231. https://doi.org/10.15390/eb.2016.6193

\section{Copyrights}

Copyright for this article is retained by the author(s), with first publication rights granted to the journal.

This is an open-access article distributed under the terms and conditions of the Creative Commons Attribution license which permits unrestricted use, distribution, and reproduction in any medium, provided the original work is properly cited. 